\title{
Yq MICRODELETIONS IN IDIOPATHIC MALE INFERTILITY
}

\section{Dinesh Kumar. V *1, Swetasmita Mishra ${ }^{2}$, Rima Dada ${ }^{2}$.}

${ }^{* 1}$ Assistant Professor, Department of Anatomy, Pondicherry Institute of Medical Sciences, Puducherry, India.

${ }^{2}$ Laboratory of molecular reproduction and genetics, All India Institute of Medical Sciences, New Delhi, India.

\section{ABSTRACT}

Introduction: Male infertility contributes to nearly $30 \%$ of the total infertile population worldwide. Genetic factors contribute to about $15 \%$ of the causes of male infertility. Systematically elucidating the underlying genetic causes (chromosomal and Yq microdeletion) may help to reduce the number of men with idiopathic infertility and provide them with the most suitable therapeutics and counseling.

Materials and methods: In this study, we performed PCR based screening for AZF microdeletions in 40 men with idiopathic infertility and 40 age-matched fertile men who served as controls.

Results and discussion: Three out of 40 (7.5\%) infertile men harboured AZF microdeletions. One patient had AZF b and two patients had AZF c microdeletions.

Conclusion: This genetic evaluation, apart from helping us to decide the treatment option, would also reduce the trauma of repeated ART failure, pregnancy loss, or the stigma of a bearing a physically, mentally, or reproductively challenged offspring.

KEY WORDS: Male infertility, AZF microdeletions, ART failure, reproductively challenged.

Address for Correspondence: Dr. Dinesh Kumar. V, Assistant Professor, Department of Anatomy, Pondicherry Institute of Medical Sciences, Puducherry, India. E-Mail: dinesh.88560@gmail.com

\begin{tabular}{|c|c|c|}
\hline \multicolumn{3}{|c|}{ Access this Article online } \\
\hline \multirow{2}{*}{ Quick Response code } & \multicolumn{2}{|c|}{$\begin{array}{l}\text { Web site: International Journal of Anatomy and Research } \\
\text { ISSN 2321-4287 } \\
\text { www.ijmhr.org/ijar.htm }\end{array}$} \\
\hline & $\begin{array}{l}\text { Received: } 12 \text { Jan } 2017 \\
\text { Peer Review: } 20 \text { Jan } 2017 \\
\text { Revised: } 02 \text { Mar } 2017\end{array}$ & $\begin{array}{l}\text { Accepted: } 16 \text { Mar } 2017 \\
\text { Published (O): } 31 \text { Mar } 2017 \\
\text { Published (P): } 31 \text { Mar } 2017\end{array}$ \\
\hline
\end{tabular}

\section{INTRODUCTION}

Infertility is a major health problem and is a complex yet common disease. It is evident from various studies that approximately $15 \%$ of the couples are unable to procreate within one year of unprotected sexual intercourse [1]. Of these the male factor is solely responsible in about $20 \%$ of the cases and is contributory in another $30-40 \%$ case [2]. The known causes of infertility are numerous and they can be grouped as congenital, anatomical, genetic and environmental. But despite extensive investigation of the male partner a large number of cases $(40-50 \%)$ remain idiopathic. Analysing the genetic factors may aid us in understanding the aetiology and thus prevent vertical transmission of these genetic abnormalities to offspring, if such couples opt for assisted conception. Yq Microdeletion is one of the genetic causes of idiopathic male infertility.

Being the only haploid component of the genome, $\mathrm{Y}$ chromosome is under the evolutionary pressure to degenerate. It has high number of direct and inverted repeats (palindromic) sequences which make the $Y$ chromosome more prone to microdeletions and intra-chromosomal 
recombinations. It accumulates mutations much higher than any autosome, as there is no recombination repair in the male specific region of $Y$ chromosome (MSY).

$Y$ chromosome microdeletions constitute the second major cause of infertility second only to Klinefelter's syndrome (polysomy of sex chromosome). The frequency of microdeletions varies between 1\% [3] to 55\% [4]. Marked variations in the frequency may be due to:

- Genetic background of various populations

- Environmental influences

- Lack of stringent inclusion criteria

- Different STS (Sequence Tagged Sites) primers used $[1,5]$.

A microdeletion is defined as a chromosomal deletion that spans several genes but that is small in size and cannot be detected using conventional cytogenetic methods like karyotyping. Y chromosome microdeletions are clustered in intervals 5 and 6 of the long arm of the $\mathrm{Y}$ chromosome. This region at $\mathrm{Yq11}$ is referred to as the "Azoospermia Factor" (AZF) region. The AZF region is further subdivided into three sub regions that are termed $A Z F a$, $A Z F b$, and AZFc.

AZFa deletion is frequently associated with Sertoli cell only syndrome. AZFb deletion may end up with spermatogenesis arrest and AZFc deletion is associated with failure of maturation process of post-meiotic germ cells [6].

$Y$ chromosome damage resulting in infertility might be regarded as another safety mechanism that serves to limit the extent to which mutations are propagated in the germ line. Moreover, because the mutation is fixed in the germ line, it has the potential to impact upon the health and well-being of all the future descendants of a given individual [7].

In this study we planned to analyse $\mathrm{Yq}$ microdeletions in cytogenetically normal men with idiopathic infertility.

\section{MATERIALS AND METHODS}

In this study, we investigated 40 men with primary infertility, referred from the Urology and Obstetrics and Gynaecology department of All India Institute of Medical Sciences (AIIMS) and
40 fertile controls (fathered a child in last 12 months). The known female factors for Infertility were ruled out after routine investigations. The ethical clearance was obtained prior to the study from the ethical committee, AIIMS (IESC/ T-283/01-07-2011) and the cases and controls were enrolled after informed ethical consent.

A detailed family, clinical, occupational and reproductive history was recorded in a predesigned Performa. The couples were evaluated to rule out congenital, immunological, endocrinal, infectious and anatomical defects, which are the common causes of male infertility.

Blood and semen samples were collected from all cases with non-obstructive azoospermia or oligozoospermia with a normal karyotype

Semen analysis: Semen samples were collected in a non-toxic, sterile container after sexual abstinence of $72-96 \mathrm{hr}$. They were then evaluated according to World Health Organization [8]. Guidelines. The parameters evaluated were $\mathrm{pH}$, semen volume $(\mathrm{ml})$, sperm concentration (million per $\mathrm{ml}$ ), total sperm count (million), progressive motility, percentage normal morphology.

Hormonal evaluation: The levels of Follicle Stimulating Hormone were evaluated in early morning samples. Serum was separated from it by centrifuging and samples were evaluated in duplicate.

Chromosome preparation and $\mathbf{g}$ banding: In all couples chromosome analysis was done to identify any numerical or structural chromosomal aberrations. For this lymphocyte cultures were setup and chromosome were analysed by $\mathrm{G}$ banding. The cytogenetic analysis was performed by a standard protocol (9). The metaphase spreads were stained in 2\% Gimesa stain, analyzed using cytovision software (ZEISS microscope) and classified according to ISCN, 2009. At least 50 metaphases were analyzed and karyotyped. Only cases which were cytogenetically normal were selected for Yq Microdeletion analysis.

\section{EVALUATION FOR AZF MICRODELETIONS}

DNA extraction from blood: Genomic DNA was extracted from peripheral blood. Five $\mathrm{ml}$ blood 
was treated with $45 \mathrm{ml}$ of lysis buffer and centrifuged at $3000 \mathrm{rpm}$ for $20 \mathrm{~min}$. Supernatant was discarded and pellet was obtained. Pellet was dissolved in $5 \mathrm{ml}$ of DNA extraction buffer. $40 \mu \mathrm{l}$ of proteinase-K of $40 \mu \mathrm{g} / \mathrm{ml}$ stock was also added. The tube was incubated at 37 ${ }^{\circ} \mathrm{C}$ overnight or at $65^{\circ} \mathrm{C}$ for 2 hours. $5 \mathrm{ml}$ of equilibrated phenol and $5 \mathrm{ml}$. of chloroform: isoamyl alcohol was added and gently mixed on rotor mixer and then centrifuged at $6500 \mathrm{rpm}$ for 10 min. Upper viscous layer was transferred with cut tip into a fresh centrifuge tube. Equal amount chloroform: isoamyl alcohol solution was added and again mixed for $10 \mathrm{~min}$ in rotor-mixer. Again upper viscous layers was transferred with a cut tip and transferred into a fresh centrifuge tube. To the aqueous solution, one-tenth volume of $3 \mathrm{M}$ sodium acetate and equal amount of ice cold ethanol was added. It was gently mixed till the DNA appears. The DNA was then spooled out using cut tips into $1.5 \mathrm{ml}$ of centrifuge tube with the help of micropipette. It was then washed twice with $70 \%$ ethanol and then was air-dried. DNA was dissolved in $500 \mu \mathrm{l}$ of TE buffer.

Quality of DNA was checked in $0.8 \%$ agarose gel, and it was quantified using nanodrop spectrophotometer. Quantification of DNA was done by observing optical density at $260 \mathrm{~nm}$ and $280 \mathrm{~nm}$. One il of aliquoted DNA solution were used for quantification of DNA on Spectronic ND-1000. The software automatically displays the quantity of DNA dissolved in $\mathrm{ng} / \mathrm{ml}$.

PCR condition for amplification: Five microlitre of total genomic DNA was subjected to 30 cycles of touchdown polymerase chain reaction in a 25 microlitre reaction. The 25 microlitre reaction mixture contain between 0.1-1 microgram of total genomic DNA ,20 pmol of each primer ,5 nmol of each dNTP, 5 microlitre of $10 x$ reaction buffer $(500 \mathrm{~mm} \mathrm{KCL}, 100 \mathrm{~nm}$ Tris-HCL, 1\% Triton $\mathrm{X}-100), 25 \mathrm{~mm} \mathrm{Mgcl} 2$ and 1 unit of Taq polymerase.

Molecular analysis for AZF loci was done using Sequence Tagged Sites (STS). Each patient was examined for different AZF loci that mapped to interval 5 and 6 of $Y$ chromosome .The sex determining region of the $\mathrm{Y}$ chromosome (SRY) with its primer sY14 was used as an internal control. Fertile male and female samples was used as positive and negative controls and water was used as blank

The following primers were used sY84, sY86 (AZFa), sY127, sY134 (AZFb), sY254 and sY255 (AZFc). The primer set as suggested by Simoni et al., (10) and recommended by the European Academy of Andrology was used. It enables detection of over $90 \%$ AZF deletions.

The samples for PCR were processed in the following manner: Initial denaturation at $95^{\circ} \mathrm{C}$ for $3 \mathrm{~min}$ was followed by 35 cycles of denaturation at $95^{\circ} \mathrm{C}$ for $30 \mathrm{~s}$, annealing at $52-60^{\circ} \mathrm{C}$ for $45 \mathrm{sec}$ and extension at $72^{\circ} \mathrm{C}$ for $1 \mathrm{~min}$.

A final extension was performed at $72^{\circ} \mathrm{C}$ for 5 $\min$

Amplification products were checked in agarose gel (1.8\%) electrophoresis before purifying PCR products for sequencing.

Agarose gel electrophoresis: The PCR products were analyzed on a $1.8 \%$ agarose gel containing ethidium bromide $(10 \mathrm{mg} / \mathrm{ml})$.

Agarose gel: Agarose gel (1.8gm) was prepared by melting the agarose in TAE buffer in microwave until the solution becomes clear. Solution was cooled to about $50-55^{\circ} \mathrm{C}$, swirling the flask occasionally to cool evenly. Then 2il ethidium bromide was added. Ends of the casting tray were sealed with two layers of tape. Combs were placed in the gel casting tray and melted agarose solution was poured into the casting tray till it solidified. The tape was removed and gel was placed in the electrophoresis chamber and enough TAE buffer was added so that there is about 2-3 $\mathrm{mm}$ of buffer over the gel. Preloading dry run was run to check integrity of wells and remove unwashed ions.

Loading the gel: Three il of sample loading dye (Xylene cyanol and Bromophenol blue) was added to each 4il PCR sample and loaded into wells. Three il, 100bp (GeneDireX) DNA ladder was added in a separate well.

Running the gel: Power supply was kept at 100 volts. Maximum allowed voltage varied depending on the size of the electrophoresis chamber. It should not exceed 5-8Volts/cm between electrodes.

\section{RESULTS}

Forty men with idiopathic male infertility and 40 fertile men (who had fathered a child in last one 
year and had normal sperm parameters) were enrolled as cases and controls. The mean age of the cases was $32.55 \pm 4.82$ years and that of the controls was $30.25 \pm 2.34$ years. In all these cases the female partner was extensively investigated clinically (gynaecological examination) and was found to be normal. All investigations (endocrinal, radiological, blood profile) were normal. This was done to exclude the female factors of infertility.

The infertile men in this study were sporadic cases with no apparent family history of infertility. Infertile men and controls had normal developmental milestones, no history of chronic obstructive pulmonary disease, infections of male accessory glands, pathologies of inguinal canal or scrotum. None of the study subjects had an occupational exposure to heat, radiation, chemicals and toxins or a recent history ( $<3$ months) of infection or drug intake.

Table 1: Comparison of semen parameters in cases and controls values are expressed as mean \pm SD

(S.C. -Sperm count, Progressive motility -grade A +B).

\begin{tabular}{|c|c|c|c|c|c|}
\hline $\begin{array}{c}\text { Category } \\
\text { (number) }\end{array}$ & $\mathrm{pH}$ & $\begin{array}{c}\text { Volume } \\
(\mathrm{ml})\end{array}$ & $\begin{array}{c}\text { Liquefaction } \\
\text { time }(\mathrm{min})\end{array}$ & $\begin{array}{c}\text { Progressive } \\
\text { motility }\end{array}$ & $\begin{array}{c}\text { S.C. } \\
\text { (million/ml) }\end{array}$ \\
\hline Case (n=40) & $7.81 \pm .275$ & $3.25 \pm 1.18$ & $32.5 \pm 4.40$ & $29.65 \pm 19.007$ & $32.05 \pm 12.65$ \\
\hline Control (n=40) & $7.78 \pm .243$ & $3.9 \pm .80$ & $30.5 \pm 4.75$ & $53.25 \pm 13.981$ & $114.5 \pm 44.8$ \\
\hline
\end{tabular}

Fig. 1: Comparison of semen parameters $(\mathrm{pH}$, volume, liquefaction time, progressive motility $A+B$ and sperm count) in cases and controls.

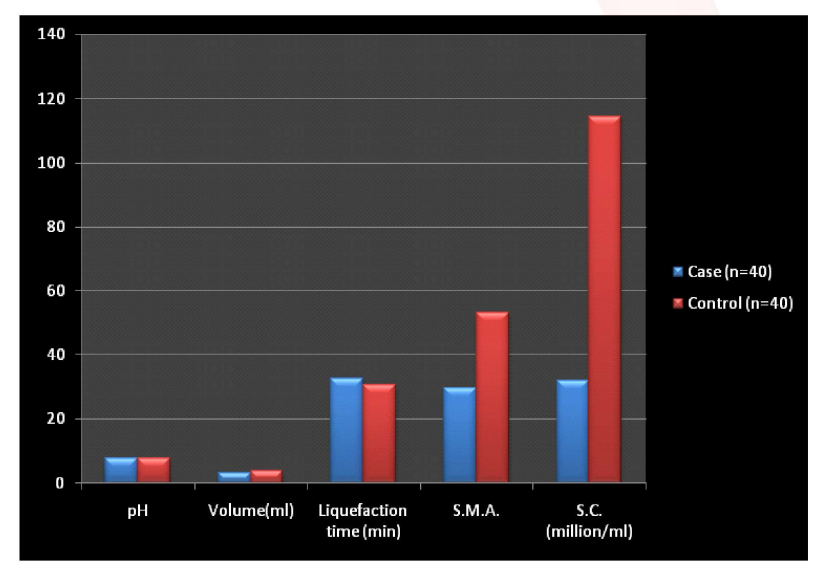

Semen analysis: Of forty infertile men, 9 cases (22.5\%) were oligozoospermic, 7 cases (17.5\%) were asthenozoospermic, 7 cases $(17.5 \%)$ were oligoasthenozoospermic, 4 cases (10\%) were azoospermic and the remaining 13 cases (32.5\%) had normal sperm parameters.
There was no significant difference in the seminal volume, $\mathrm{pH}$, liquefaction time and viscosity between cases and controls.

In this study, the mean \pm S.D. of progressive motility $(A+B)$ in the controls was significantly higher $\left({ }^{\prime} t '=6.32 ; p<0.05\right)$ than in cases. The mean \pm S.D. of the cases was $29.65 \pm 19.007$ and that of controls was $53.25 \pm 13.981$. The motility grade $A\left({ }^{\prime}{ }^{\prime}=5.1 ; p<0.05\right)$ and grade $B$ $\left({ }^{\prime} t=3.6 ; p<0.05\right)$ were significantly higher in controls when compared to grade $C\left({ }^{\prime} t '=0.76\right.$; $p>0.05)$ and grade $D(' t '=0.58 ; p>0.05)$.

The mean \pm S.D. of sperm count in the controls was significantly higher $\left({ }^{\prime} \mathrm{t}\right.$ ' $\left.=11.2 ; \mathrm{p}<0.05\right)$ than in the cases. The mean \pm S.D. of the cases was $32.05 \pm 12.65$ and that of controls was $114.5 \pm$ 44.8.

Table 2: Age, Duration of infertility, Endocrinal levels, \% of progressive motility (grade $A+B$ ), sperm count of Infertile men and controls

\begin{tabular}{|c|c|c|c|c|c|}
\hline $\begin{array}{c}\text { Infertile men with sperm } \\
\text { pathologies }\end{array}$ & Age & $\begin{array}{c}\text { Duration of } \\
\text { infertility }\end{array}$ & FSH (mlU/L) & $\begin{array}{c}\text { \% of } \\
\text { progressive } \\
\text { Motility (A+B) }\end{array}$ & $\begin{array}{c}\text { S.C. } \\
\text { (million/ml) }\end{array}$ \\
\hline $\mathrm{O}(\mathrm{n}=9)$ & $28.5 \pm 5.1$ & $4.98 \pm 1.8$ & $20.4 \pm 2.7$ & $39.3 \pm 7.2$ & $9.5 \pm 3.8$ \\
\hline $\mathrm{A}(\mathrm{n}=7)$ & $32.6 \pm 4.8$ & $5.2 \pm 2.1$ & $18.7 \pm 1.7$ & $10.5 \pm 4.5$ & $5.6 \pm 2.6$ \\
\hline $\mathrm{OA}(\mathrm{n}=7)$ & $34.3 \pm 3.8$ & $6.3 \pm 2.4$ & $12.4 \pm 1.2$ & $9.1 \pm 6.8$ & $33.5 \pm 10.3$ \\
\hline $\mathrm{AZ}(\mathrm{n}=4)$ & $34.7 \pm 3.9$ & $3.4 \pm 1.5$ & $29.5 \pm 4.3$ & - & - \\
\hline $\mathrm{NZ}(\mathrm{n}=13)$ & $30.2 \pm 3.2$ & $6.2 \pm 1.9$ & $9.2 \pm 1.8$ & $58.75 \pm 7.8$ & $65.5 \pm 25.4$ \\
\hline Controls $(\mathrm{n}=40)$ & $29.1 \pm 1.8$ & - & $7.6 \pm 2.3$ & $67.43 \pm 10.3$ & $114.5 \pm 44.8$ \\
\hline
\end{tabular}

[O -Oligozoospermia, A - Asthenozoospermia,

[O -Oligozoospermia, A - Asthenozoospermia,

$O A$ - Oligoasthenozoospermia,

$\mathrm{AZ}$ - Azoospermia, NZ - normozoospermia]

$O A$ - Oligoasthenozoospermia, AZ - Azoospermia, $\mathrm{NZ}$ - normozoospermia]

Fig.2: comparison of sperm parameters (progressive motility and sperm count) among different subpopulation of cases.

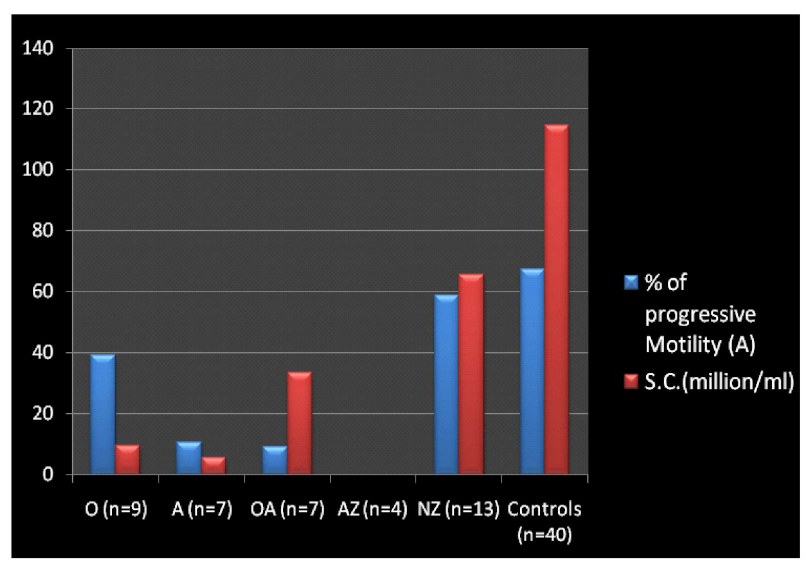

Cytogenetic analysis: Cytogenetic analysis using $\mathrm{G}$ banding Karyotyping ( 450 band resolution) was done in cases, controls and their 
female partners. On cytogenetic analysis it was found that both male and female partners were cytogenetically normal and had normal $46, X Y$ and $46, X X$ chromosomal complement respectively (Fig. 2)

Fig.3: Electrophoresis on a $1.8 \%$ agarose gel showing deletions in the AZF region of the $Y$ chromosome $L$ - Base pair Marker (Msp1 digest), 1-infertile case with no Yq microdeletion depicted by three bands of appropriate size, 2- AZF b deleted infertile men, 3- AZF c deleted infertile men, 4-Positive control, 5-Negative control, 6- blank; water sample that contains all reaction components but water instead of DNA for reagent contamination; SRY- internal control (472bp).

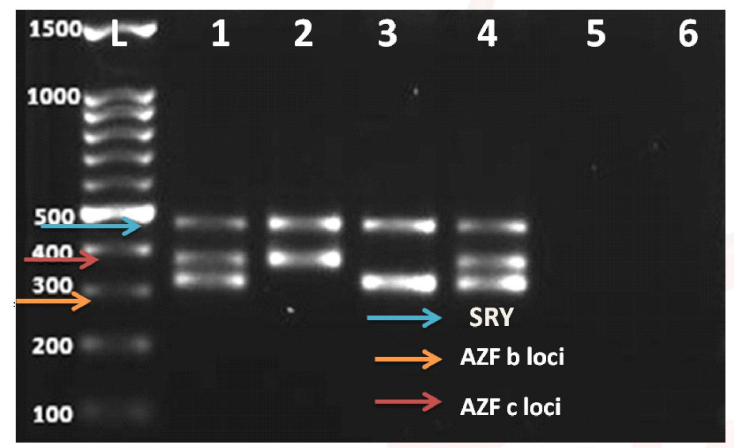

Fig.4: Electrophoresis on a $1.8 \%$ agarose gel showing deletion in the AZF c region of the $Y$ chromosome $L$ - Base pair Marker (Msp1 digest), 2- AZF b deleted infertile case, 1 -infertile case with no AZF b Microdeletion as depicted by band of 274 bp size, 3- Positive control, 4- Negative control, 5- Blank; water sample that contains all reaction components but water instead of DNA for reagent contamination.

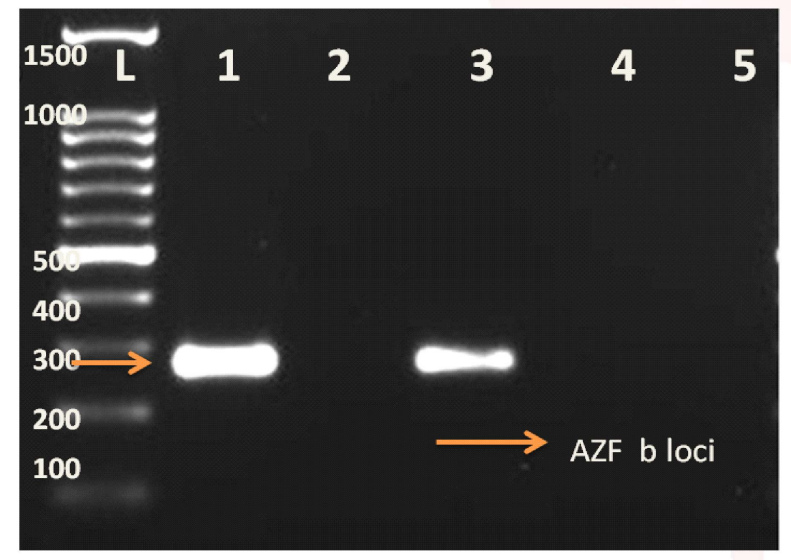

Yq Microdeletion analysis: Microdeletions of the $\mathrm{Y}$ chromosome [AZFa, AZFb and AZFc regions] were analyzed in blood and sperm DNA (in non-azoospermic infertile men) using a PCR - based non-polymorphic STS markers.

$Y$ chromosome microdeletions were observed in 3 out of 40 infertile men and none in the controls. In genomic DNA isolated from blood in 40 infertile men, AZFb (sY 127, 134) was deleted in one case, while AZFc (sY 254, 255) was deleted in two cases. Sperm DNA also revealed identical deletions in AZFb and AZFc loci.

The case with AZFb microdeletion had elevated FSH levels of $28.3 \mathrm{mIU} / \mathrm{L}$ (normal FSH $=4.6-12.4$ $\mathrm{mIU} / \mathrm{L}$ ). This case was azoospermic.

One AZFc deleted case had elevated FSH levels of $39.7 \mathrm{mIU} / \mathrm{L}$ and was azoospermic. Second case with AZFc deletion had normal FSH level.(FSH level=9.6 $\mathrm{mIU} / \mathrm{L}$ ) and had severe oligozoospermia (2.1 million/ml)

\section{DISCUSSION}

Male infertility is considered to be a multifactorial disorder affected by genetic, environmental and hormonal factors. Y chromosome microdeletion is the most frequent known molecular genetics cause of severe impairment of spermatogenesis. Its frequency is about $10 \%$ in non-obstructive azoospermic and $3-5 \%$ in idiopathic severe oligozoospermic men [11]. The identiûcation of $\mathrm{Yq}$ microdeletions is not only relevant for the diagnosis but it may have prognostic value prior to testicular biopsy for sperm extraction (TESE) $[12,13]$. The Yq deleted cases may be azoospermic or oligozoospermic depending upon the genes deleted and extent of deletion in the AZF gene complex. Those Yq deletions which are compatible with the presence of spermatozoa in the ejaculate are obligatorily transmitted to the male offspring; therefore genetic counseling is mandatory in these patients.

Apart from the few inherited cases, which have been genetically transmitted most of the $Y$ chromosome deletions occur as de novo events. The cellular origin and the mechanism of $Y$ chromosome deletions are not clear. Presumably, the deletions are preceded by double-strand breaks that, if they occurred pre-meiotic, could lead to the presence of $Y$ chromosome deletions in the ejaculated spermatozoa. Alternatively, the spermatozoa may harbor a high frequency of double-strand breaks that lead to the creation of deletions after fertilization.

The etiology of these strand breaks may involve aberrant recombination, defective chromatin packaging, abortive apoptosis and oxidative stress. Oxidative stress leads to generation of mutagenic bases such as 8-oxoguanosine which leads to GC to TA transversions and eventually 
to single and double strand breaks. Only base excision repair remains active in sperm and thus sperm DNA damage is repaired by the oocyte post fertilization. This oocyte repair depends on DNA integrity of oocyte and also extent of sperm DNA damage.

In this study, men with idiopathic infertility were evaluated in a comprehensive, step-wise fashion to investigate the contribution of genetic and oxidative stress factors in infertility.

In this study, both infertile men and controls were evaluated for the presence of chromosomal abnormalities. All the cases had normal karyotype with $46, \mathrm{XY}$ chromosomal complement and only these cases were included for further analysis.

AZF microdeletion analysis is essential to prevent iatrogenic transmission of the same deletion or larger, secondary deletions to male offspring in ART [14].

AZF microdeletions are pro-mutagenic and make the $Y$ chromosome unstable and may lead to secondary larger deletions or complete loss of $Y$ chromosome, thereby increasing the risk of mosaicism $(46, \mathrm{XY} / 45, \mathrm{XO})$ and genital ambiguity in offspring. This may actually result in the doubling of the infertile population [14-18].

In this study, we had categorized the cases $(n=40)$ based on semen analysis into oligozoospermic, asthenozoospermic, oligoasthenozoospermic, azoospemic and normozoospermic. Of this, 3 cases were azoospermic and one case had severe oligozoospermia. 3 of the 4 case had AZF microdeletion, constituting 7.5\% of infertile men and one case did not harbour AZF microdeletion. The reported prevalence of microdeletions in infertile men varies among studies from $1 \%$ to $55 \%[3,19,20]$. This variation may be due to non-stringent inclusion criteria and the use of a large number of polymorphic STS markers. Previous studies by Dada $R$ et al. $[20,21]$ showed that following European Academy of Andrology guidelines [22] and stringent inclusion and exclusion criteria, the frequency of deletion in Indian population is similar to Danish, French and Italian populations.

The prevalence of Y-chromosome microdeletions is estimated to be about 1 in 2000 to 1 in 3000 males; the frequency in males with azoosperm- ia or severe oligozoospermia is about $5 \%-12 \%$, although a marked difference is reported in different parts of the world [23].

In this study, 2 out of the 3 AZF deleted cases had elevated FSH levels, indicative of severe testiculopathy. In one of the AZFc deleted case, the FSH level was in the normal range $(9.6 \mathrm{mIU} /$ L). AZFc deletions lead to variable testicular phenotype and in cases of severe impairment of spermatogenesis FSH level is usually increased above the normal range $(>8 \mathrm{mIU} / \mathrm{L}$ ) [24]. Both FSH values and testis volume reûects the degree of spermatogenic impairment (the more severe forms are associated with the highest FSH values and lowest testicular volume). However there is no absolute FSH value or testis size to predict the presence/absence of spermatozoa in the testis of an azoospermic man but cases with FSH $>25 \mathrm{mIU} / \mathrm{L}$ are usually cases with no sperm in the testis. Moderate/ mild oligozoospermia and azoospermia due to spermatogenic arrest (meiotic or post-meiotic phases) are typically associated with normal FSH and normal testis volume.

Deletions of the AZFb region cause arrest of spermatogenesis at the primary spermatocyte stage [25], indicating that the region is essential for fertility [26]. The main gene RBMY1 is expressed in the nuclei of primary spermatocytes, spermatogonia and spermatids and is involved in RNA processing.

AZFc deletions are the underlying aetiology in about $12 \%$ cases of nonobstructive azoospermia and $6 \%$ cases of severe oligozoospermia [27]. As the AZFc deletion spans a $3.5 \mathrm{Mb}$ region and contains 8 gene families, the phenotype can vary from azoospermia to mild or severe oligozoospermia and also there are multiple copies of DAZ gene and it also has an autosomal homologue on chromosome 3 [25]. The AZFc region is prone to many smaller subdeletions (eg: $\mathrm{gr}$ / gr, b2/b3) that are thought to be caused by intrachromosomal recombination [28]. The heterogeneities recorded for partial AZFc deletions reflect on two different levels (i) when comparing between different partial patterns (ii) when analysing phenotype diversity associated with single pattern $[29,30]$. More detailed analysis should be done to diagnose the type of partial deletions according to the ethnic population as 
in certain populations such sub deletions have been found in.

In this study, $7.5 \%$ of infertile men harboured $\mathrm{Yq}$ microdeletions. Of this, $2.5 \%$ had AZFb deletion and $5 \%$ had AZFc deletion and none had AZFa deletion. Our results are in concordance (though slightly lower) with the data published [31], which states that the relative frequency of individual microdeletions are $60 \%, 5 \%$ and $16 \%$ for AZFc, AZFa and AZFb regions.

Don Kyung Choi et al., [32] observed an association between $Y$ chromosome microdeletions and birth rates with multiple TESE. More spermatozoa were retrieved in patients with AZFC microdeletion with multiple TESE than in patients with AZFb-c microdeletion (8/21 [38.0\%] vs. $0 / 9$ [0\%], $p=0.041)$. The type of $Y$ chromosome microdeletion (AZFa, b, c) has been proposed as a potential prognostic factor for sperm retrieval in men undergoing multiple TESE $[33,34]$. Deletions including and extending beyond the AZFc region (i.e., AZFb-c, AZFa-b-c) have been correlated with the complete absence of testicular spermatozoa, and the presence of an AZFb microdeletion is a significantly adverse prognostic finding for multiple TESE.

In the long term, absolute selection against males with deletions (such as AZF) that confer sex reversal or sterility will create strong pressure either to retain (and amplify) fertility genes, or for any fertile variant that replaces it [35]. The presence of many genes that have lost their function (pseudogenes) on the $Y$ chromosome indicates that this process of attrition is continuing, so that even the key genes may be lost. However the $Y$ chromosome has amplified the genes which enhance male fitness except the SRY gene on its short arm.

\section{CONCLUSION}

From the present study, it can be emphasized that evaluation of $Y$ chromosome microdeletions in infertile men with non-obstructive azoospermia and severe oligozoospermia should be performed before undertaking assisted reproductive techniques, such as multiple TESE and ICSI.

\section{Conflicts of Interests: None}

\section{REFERENCES}

[1]. Poongothai J, Gopenath T S. Genetics of human infertility; Singapore Medical Journal 2009;50(4);336.
[2]. Krausz $C$ et al., Male infertility pathogenesis and clinical diagnosis: Best practice and Research of Clinical Endocrinology and Metabolism 2011;25:271-285.

[3]. van der Ven K, Montag M, Peschka B, Leygraaf J, Schwanitz G, Haidl G, Krebs D, van der Ven H. Combined cytogenetic and $\mathrm{Y}$ chromosome microdeletion screening in males undergoing intracytoplasmic sperm injection. Mol Hum Reprod1997;3:699-704.

[4]. Foresta C, Ferlin A, et al., Y chromosome microdeletions in idiopathic severe testiculopathiesJ.Clin.Endocrinol.Metabol. 1997;82:10751080.

[5]. Dada R et al., Molecular screening for Yq microdeletion in men with idiopathic azoospermia and oligozoospermia; J Biosci.28, 2003;163-168.

[6]. Dr. Kyumars Safinejad et al., Y chromosome Microdeletions in Infertile Men with Severe Oligozoospermia; J. Basic Appl. Sci. Res., 2013;3(2):786791.

[7]. Krausz C, Rajpert-De Meyts E, Frydelund-Larsen L, Quintana-Murci L, McElreavey K, et al. Double-blind $Y$ chromosome microdeletion analysis in men with known sperm parameters and reproductive hormone profiles: microdeletions are specific for spermatogenic failure. J Clin Endocrinol Metab, 2001;86:2638-2648.

[8]. WHO Laboratory Manual for the Examination of Human Semen and Semen Cervical Mucus Interaction. 4 ed. Cambridge, UK: Cambridge University Press, 1999.

[9]. Rooney DE, Czepulkowski BH.. Human cytogeneticsessential data. Chichester: John Wiley and Sons.1999.

[10]. Simoni M, Bakker E, Eurlings MC, Matthijs G, Moro $E$, Muller $C R$, et al. Laboratory guidelines for the molecular diagnosis of $Y$ chromosomal microdeletions. Int J Androl, 1999;22:292-299.

[11]. Krausz C \& Degl'Innocenti S. Y chromosome and male infertility: update, 2006. Frontiers in Bioscience 2006;11:3049-3061.

[12]. Brandell RA, Mielnik A, Liotta D, Ye Z et al. AZFb deletions predict the absence of spermatozoa with testicular sperm extraction: preliminary report of a prognostic genetic test. Human Reproduction 1998;13:2812-2815.

[13]. Krausz C, Quintana-Murci L \& McElreavey K. Prognostic value of $Y$ deletion analysis: what is the clinical prognostic value of $Y$ chromosome microdeletion analysis? Human Reproduction 2000;15:1431-1434.

[14]. Dada R, Kumar R, Shamsi MB, Tanwar M, Pathak D, Venkatesh S, Kumar M, Singh $H$, Singh K, Aron M, Kumar R, Singh G, Sharma RK, Gupta NP. Genetic screening in couples experiencing recurrent assisted procreation failure. Indian J Biochem Biophys, 2008;45:116-120.

[15]. Aitken RJ, Krausz C. Oxidative stress, DNA damage and $Y$ chromosome. Reproduction, 2001;122:497506. 
[16]. Aitken RJ, Baker MA, Sawyer D. Oxidative stress in the male germ line and its role in the etiology of male infertility and genetic disease. Reprod Biomed Online 2003;7:65-70.

[17]. Vogt PH, Edelmann A, Kirsch S, Henegariu O, Hirschmann $P$,. Human $Y$ chromosome azoospermia factors (AZF) mapped to different subregions in Yq11. Hum Mol Genet 2004;5:933-943.

[18]. Oates RD, Lamb D. Genetic aspects of male infertility. In: Lipshultz LI, Howard S, Niederberger C, editors. Infertility in the male, $4^{\text {th }}$ edition. Cambridge: Cambridge University Press. 2009;251-276.

[19]. Reijo R, Alagappan RK, Patrizio P, Page DC. Severe oligospermia resulting from deletions of azoospermia factor gene on $Y$ chromosome. Lancet, 1996;347:1290- 1293.

[20]. Dada R, Kumar R, Shamsi MB, Kumar R, Kucheria K, Sharma RK, Gupta SK, Gupta NP. Higher frequency of Yq microdeletions in sperm DNA as compared to DNA isolated from blood. Asian J Androl, 2007;9:720722.

[21]. Dada R, Gupta NP, Kucheria K. Yq microdeletions azoospermia factor candidate genes and spermatogenic arrest. J Biomol Tech, 2004;15:176-183.

[22]. Simoni M, Bakker E, Krausz C. EAA/EMQN best practice guidelines for molecular diagnosis of $y$-chromosomal microdeletions. State of the art. Int J Androl, 2004;27:240-249.

[23]. Simoni M Clinical consequences of microdeletions of the Y chromosome: the extended Münster experience. RBM online 2008;16:289-30.

[24]. Andersson AM, Petersen JH, Jorgensen N, Jensen TK et al. Serum inhibin $B$ and follicle-stimulating hormone levels as tools in the evaluation of infertile men: signiûcance of adequate reference values from proven fertile men. Journal of Clinical Endocrinology and Metabolism 2004;89:2873-2879.

[25]. Vogt P. H. AZF deletions and Y chromosomal haplogroups: history and update based on sequence. Human Reproduction Update, 2005;11(4):319-336.

[26]. Nuti F \& Krausz C. Gene polymorphisms/mutations relevant to abnormal spermatogenesis. Reproductive Biomedicine Online 2008;16:504-513.

[27]. Kuroda-Kawaguchi T, Skaletsky H, Brown LG, Minx PJ, Cordum HS, Waterston RH, Wilson RK, Silber S, Oates $R$, Rozen $S$ et al., The AZFc region of the $Y$ chromosome features massive palindromes and uniform recurrent deletions in infertile men Nat Genet, 2001;29:279-286.
[28]. Ferlin A, Raicu F, Gatta V, Zuccarello D, Palka G, Foresta C. Male infertility: Role of genetic background. Reprod Biomed Online, 2007;14:734-745.

[29]. Fernandes S, Paracchini S, Meyer LH, Floridia G, Tyler-Smith $\mathrm{C}$ and Vogt $\mathrm{PH}$. A large AZFc deletion removes DAZ3/DAZ4 and nearby genes from men in Y haplogroup N. Am J Hum Genet, 2004;74:80-187.

[30]. Balaresque P, Bowden GR, Parkin EJ, Omran GA, Heyer E, Quintana-Murci L, Roewer L, Stoneking M, Nasidze I, Carvalho-Silva DR et al. Dynamic nature of the proximal AZFc region of the human $Y$ chromosome: multiple independent deletion and duplication events revealed by microsatellite analysis. Hum Mutat2008;29:1171-1180.

[31]. Shefi S, Turek PJ Definition and current evaluation of subfertile men. Int Braz J Urol. 2006;32:385-97.

[32]. Don Kyung Choi, In Hyuck Gong, Jin Ho Hwang, Jong Jin Oh, Jae Yup Hong Detection of Y Chromosome Microdeletion is Valuable in the treatment of $\mathrm{Pa}$ tients With Nonobstructive Azoospermia and Oligoasthenoteratozoospermia: Sperm Retrieval Rate and Birth Rate Korean J Urol 2013;54:111-116.

[33]. Oliva R, Margarit E, Ballescá JL, Carrio A, Sanchez A, Mila $M$ et al. Prevalence of $Y$ chromosome microdeletions in oligospermic and azoospermic candidates for intracytoplasmic sperm injection. Fertil Steril 1998;70:506-10.

[34]. Mulhall JP, Reijo R, Alagappan R, Brown L, Page D, Carson $\mathrm{R}$ et al. Azoospermic men with deletion of the DAZ gene cluster are capable of completing spermatogenesis: fertilization, normal embryonic development and pregnancy occur when retrieved testicular spermatozoa are used for intracytoplasmic sperm injection. Hum Reprod 1997;12:503-8.

[35]. Aitken .R.J. and J. A. Marshall Graves. The future of sex NATURE 2002;415(28):963.

How to cite this article:

Dinesh Kumar. V, Swetasmita Mishra, Rima Dada. Yq MICRODELETIONS IN IDIOPATHIC MALE INFERTILITY. Int J Anat Res 2017;5(1):3579-3586. DOI: 10.16965/ijar.2017.113 